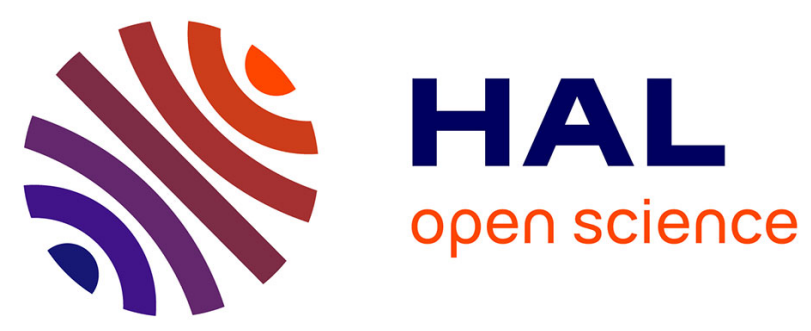

\title{
Helicobacter pylori's cholesterol uptake impacts resistance to docosahexaenoic acid
}

Marta Correia, Susana Casal, João Vinagre, Raquel Seruca, Ceu Figueiredo, Eliette Touati, Jose Carlos Machado

\section{- To cite this version:}

Marta Correia, Susana Casal, João Vinagre, Raquel Seruca, Ceu Figueiredo, et al.. Helicobacter pylori's cholesterol uptake impacts resistance to docosahexaenoic acid. International Journal of Medical Microbiology, 2014, 304 (3-4), pp.314-320. 10.1016/j.ijmm.2013.11.018 . hal-01651988

\section{HAL Id: hal-01651988 \\ https://hal.science/hal-01651988}

Submitted on 20 Mar 2018

HAL is a multi-disciplinary open access archive for the deposit and dissemination of scientific research documents, whether they are published or not. The documents may come from teaching and research institutions in France or abroad, or from public or private research centers.
L'archive ouverte pluridisciplinaire HAL, est destinée au dépôt et à la diffusion de documents scientifiques de niveau recherche, publiés ou non, émanant des établissements d'enseignement et de recherche français ou étrangers, des laboratoires publics ou privés.

\section{(1) (1) $\$$}

Distributed under a Creative Commons Attribution - NonCommercial - NoDerivatives 44.0 
1 Helicobacter pylori's cholesterol uptake impacts resistance to

2 docosahexaenoic acid

3 Marta Correia ${ }^{1,2,3}$, Susana Casal ${ }^{4}$, João Vinagre ${ }^{1,2,5}$, Raquel Seruca ${ }^{1,2}$, Ceu

4 Figueiredo ${ }^{1,2}$, Eliette Touati ${ }^{3}$, José C Machado ${ }^{1,2 \#}$

$6{ }^{1}$ Institute of Molecular Pathology and Immunology of the University of Porto,

7 Portugal. Rua Dr. Roberto Frias s/n 4200-465-Porto, Portugal;

$8 \quad{ }^{2}$ Faculdade de Medicina da Universidade do Porto, Portugal. Al. Prof. Hernâni

9 Monteiro 4200 - 319 Porto Portugal.

10 Institut Pasteur, Unité de Pathogenèse de Helicobacter, Paris, France. 25,28 rue

11 du Docteur Roux 75724 Paris CEDEX 15 - France.

$12{ }^{4}$ REQUIMTE/Laboratório de Bromatologia e Hidrologia, Faculdade de Farmácia do

13 porto Rua de Jorge Viterbo Ferreira, 228, 4050-313, Porto, Portugal.

$14{ }^{5}$ Institute of Biomedical Sciences Abel Salazar of the University of Porto (ICBAS),

15 4099-003 Porto, Portugal.

16 \#Corresponding author

17 - Dr. JC Machado, IPATIMUP, Rua Dr. Roberto Frias, s/n, 4200-465 Porto,

18 Portugal;Tel:00351225570700;Fax:00351225570799,josem@ipatimup.pt.

19 Keywords:

20 Bactericidal agents; Helicobacter pylori; Mechanisms of resistance; Cholesterol;

21 PUFAs 
23 Abstract Helicobacter pylori colonizes half of the world population and is associated

24 with gastric cancer. We have previously demonstrated that docosahexaenoic acid

25 (DHA), an n-3 polyunsaturated fatty acid known for its anti-inflammatory and

26 antitumor effects, directly inhibits $H$. pylori growth in vitro and in mice. Nevertheless,

27 the concentration of DHA shown to reduce H. pylori mice gastric colonization was

28 ineffective in vitro. Related to the auxotrophy of $H$. pylori for cholesterol, we

29 hypothesize that other mechanisms, in addition to DHA direct antibacterial effect,

30 must be responsible for the reduction of the infection burden. In the present study

31 we investigated if DHA affects also $H$. pylori growth, by reducing the availability of

32 membrane cholesterol in the epithelial cell for $H$. pylori uptake. Levels of cholesterol

33 in gastric epithelial cells and of cholesteryl glucosides in $\mathrm{H}$. pylori were determined

34 by thin layer chromatography and gas chromatography. The consequences of

35 epithelial cells' cholesterol depletion on $H$. pylori growth were assessed in liquid

36 cultures. We show that $H$. pylori uptakes cholesterol from epithelial cells. In addition,

37 DHA lowers cholesterol levels in epithelial cells, decreases its de novo synthesis,

38 leading to a lower synthesis of cholesteryl glucosides by $H$. pylori. A previous

39 exposition of $H$. pylori to cholesterol influences the bacterium response to the direct

40 inhibitory effect of DHA. Overall, our results suggest that a direct effect of DHA on

$41 H$. pylori survival is modulated by its access to epithelial cell cholesterol, supporting

42 the notion that cholesterol enhances the resistance of $H$. pylori. The cholesterol-

43 dependent resistance of $H$. pylori to antimicrobial compounds raises new important

44 aspects for the development of new anti-bacterial strategies. 


\section{Introduction}

$46 H$. pylori colonizes half of the world population and is associated with dyspepsia,

47 chronic gastritis, ulcer disease and gastric cancer. (Peek and Crabtree, 2006)

48 Eradication of this infection leads to a reduction in the recurrence of peptic ulcer

49 disease and prevents the development of gastric precancerous lesions (Talley et al.,

50 2008), highlighting the need for new therapeutic strategies to treat $H$. pylori carriers.

51 Usually, the first-line option for eradicating $H$. pylori infection is a triple treatment that

52 consists of a proton pump inhibitor (PPI) and two antimicrobial agents. (Malfertheiner

53 et al., 2007) However, the increasing incidence of bacteria strains resistant to these

54 antibiotics is partially responsible for failure of treatment reported for triple therapy.

55 (Gisbert et al., 2010) Thus, new alternative therapies that improve the eradication

56 rate of $H$. pylori and that circumvent the antibiotics resistance are of great interest.

57 According to a previous study (Thompson et al., 1994), we have demonstrated that

58 polyunsaturated fatty acids (PUFAs) and in particular docosahexaenoic acid (DHA),

59 which is a n-3 PUFA, hold an anti-H. pylori growth action. DHA inhibits $H$. pylori

60 growth in a concentration dependent manner in vitro, and this was confirmed in a

61 murine model.(Correia et al., 2012) Our previous data also suggest that this

62 inhibitory effect involves the incorporation of DHA into the bacterium's cell wall,

63 inducing changes in the components of the cell wall and facilitating bacteria lysis.

64 (Correia et al., 2012) Nevertheless, the concentration of $50 \mu \mathrm{M}$ of DHA shown to 65 reduce $H$. pylori mice gastric colonization was not effective in vitro. (Correia et al., 66 2012) These results are in line with the fact that other mechanisms in addition to a 67 DHA direct antibacterial effect on $H$. pylori, must be responsible for the reduction of 
H. pylori load in the stomach of infected mice treated with DHA. In this context, we

69 cannot exclude that the direct action of DHA on epithelial cells impacts its anti-

70 Helicobacter effect besides affecting bacteria. In fact, it is well recognized that DHA

71 is incorporated into cell membrane of eukaryotic cells leading to alteration of

72 membrane physical properties such as permeability, lateral diffusion, lipid packing,

73 domain formation and cholesterol availability/distribution.(Shaikh et al., 2004)

74 Interestingly, cholesterol rich-platforms within cell membranes have been implicated

75 as cell gates for pathogens.(Xiong et al., 2009) Moreover, the genus Helicobacter

76 has the unique feature of assimilating free cholesterol (FC) extracted from epithelial

77 lipid rafts into its bacterial outer membrane, allowing its enzymatic

78 glycosylation.(Wunder et al., 2006) The cgt H. pylori mutant, which lacks the ability

79 to biosynthesize the glycosyl cholesterol and retains FC without glycosylation, is

80 easily phagocytized by macrophages and induces activation of antigen-specific $T$

81 cells. These features highlight the importance of cholesterol metabolism in the

82 bacteria survival and ability to colonize.(Shimomura et al., 2004; Wunder et al., 2006)

83 Moreover, the translocation of $H$. pylori virulence factors, such as vacuolating

84 cytotoxin $A(\operatorname{Vac} A)$ and cytotoxin associated gene $A(C a g A)$, via the type IV secretion

85 system (TFSS), depends on the FC level of epithelial cell, as they are blocked by

86 cholesterol depletion (ex: cyclodextrins).(Lai et al., 2008; Patel et al., 2002) The

87 glycosyl cholesterol also modifies lateral-phase segregation in epithelial cell

88 membranes, reorganizing the architecture of the membrane and promoting the

89 formation of a functional TFSS.(Wang et al., 2012) Hence, glycosylation of

90 cholesterol plays an important role in H. pylori survival. 
91 Given the known ability of n-3 PUFAs, and DHA in particular, to interfere with

92 cholesterol's distribution in the epithelial cell membrane and given the auxotrophy of

93 H. pylori for cholesterol, we hypothesized that besides its direct antibacterial effect,

94 DHA holds an indirect effect on $H$. pylori growth. This indirect effect might be

95 achieved through mechanisms that involve DHA ability to interfere with cholesterol

96 in epithelial cells. Additionally, statins, that as DHA, affect cholesterol metabolism,

97 increase the eradication of $H$. pylori infection when used as co-adjuvant to standard

98 triple therapy (Nseir et al., 2012). In this study we aim to further characterize the

99 mechanisms by which DHA holds an anti-H. pylori activity. We investigate if in

100 addition to its direct bactericidal action, DHA exerts an indirect effect on $H$. pylori by

101 modulating epithelial cells' cholesterol uptake. 


\section{MATERIAL AND METHODS}

103 Fatty acids, $\boldsymbol{H}$. pylori strains and cell culture conditions

104 DHA was obtained from Cayman Chemical Company (Michigan, USA) with a degree 105 of purity of $99 \%$ in ethanol $0.06 \%(v / v)$. The $H$. pylori strains used were: SS1 (Lee et 106 al., 1997) 26695 (ATCC 700392) obtained from the American Type Culture 107 Collection (ATCC, Rockville, MD). H. pylori was grown on blood agar base 2 plates 108 (Oxoid, Lyon, France) supplemented with 10\% defibrinated horse blood (bioMérieux, 109 Marcy l'Etoile, France). Plates were incubated at $37^{\circ} \mathrm{C}$ for $48 \mathrm{~h}$ under microaerobic 110 conditions $\left(7 \% \mathrm{O}_{2}, 10 \% \mathrm{CO}_{2}\right.$; anoxomat system). Cell infections were performed with

$111 H$. pylori grown in liquid cultures. Briefly, bacteria were inoculated to an initial optical

112 density of 0.03 at $600 \mathrm{~nm}$ into liquid Brucella broth (BB) (Oxoid) supplemented with $11310 \%$ fetal calf serum (FCS). H. pylori grown for 18-20h yields approximately $5 \times 10^{8}$ 114 colony forming units (CFU)/ml. Bacterial cholesterol analysis was performed with $H$. 115 pylori strain 26695, due to the fact that this strain has a functional TFSS, described 116 to be sensitive to host epithelial cholesterol. (Wang et al., 2012)

117 Human gastric epithelial cells (AGS: gastric adenocarcinoma, CRL-1739, ATCC118 LGC $^{\circledR}$ ) were grown in RPMI medium 1640 supplemented with $10 \%$ FCS and $1 \%$ of 119 penicillin-streptomycin under $37^{\circ} \mathrm{C}$ and under $5 \% \mathrm{CO} 2$ in humidified air. For cell 120 viability assays, cells were trypsinized and counted using trypan blue (Sigma121 Aldrich) staining. Liquid cultures of $H$. pylori were added to AGS cells in serum free 122 medium for at least 18h, at a multiplicity of infection (MOI) of 100:1 and kept under

123 agitation for $1 \mathrm{~h}, 6 \mathrm{~h}$ or $24 \mathrm{~h}$ at $37^{\circ} \mathrm{C}$. Treatment with cholesterol rich-microdomains 124 disruptors in AGS cells was performed with methyl- $\beta$-cyclodextrin (MBCD; Sigma- 
125 Aldrich). Briefly, AGS cells were washed with PBS three times and treated with 2.5 $126 \mathrm{mM}$ of $\mathrm{MBCD}$ for $1 \mathrm{~h}$ at $37^{\circ} \mathrm{C}$. To remove MBCD cells were washed with PBS three 127 times.

Incubation of AGS cells with 25-benz-oxa-diazol- (NBD)-labeled cholesterol 130 and with DHA

131 Stock solutions of 25-benz-oxa-diazol-labeled cholesterol (NBD-cholesterol) (Avanti

132 Polar Lipids) were solubilized in ethanol and stored at $-20^{\circ} \mathrm{C}$, at a final concentration

133 of $5 \mu \mathrm{g} / \mathrm{ml}$ NBD-cholesterol. AGS cells were used as cholesterol suppliers for $H$.

134 pylori uptake, because of previous demonstration that the bacteria extracts 135 cholesterol from epithelial cells in a more efficient way than it extracts from liquid 136 medium. (Wunder et al., 2006). In order to verify that epithelial cells had cholesterol 137 available for $H$. pylori uptake, confluent AGS monolayers cells grown in a serum-free 138 RPMI medium for $3 \mathrm{~h}$, were labeled with NBD-cholesterol $(5 \mu \mathrm{g} / \mathrm{ml}$ NBD-cholesterol 139 and ethanol concentration $0.25 \% \mathrm{v} / \mathrm{v}$ ). Cells were then washed with PBS to remove 140 unbound NBD-cholesterol and treated with DHA 50 $\mu$ M in RPMI medium for $12 \mathrm{~h}$. This 141 concentration was shown to be within the range of non-toxic concentrations 142 according to trypan blue exclusion test (data not shown). After DHA treatment, AGS 143 cells were vigorously washed with PBS and put into a DHA-free fresh medium for

$14418 \mathrm{~h}$ to exclude other sources of cholesterol than the ones present in epithelial cell 145 membranes. Cells were then infected with H. pylori at MOI of 100:1 for $3 \mathrm{~h}$.

147 DHA treatment of $\boldsymbol{H}$. pylori cultures 
148 Stock solutions of DHA were diluted in BB enriched with $10 \%$ FCS and used at 149 concentrations of $100 \mu \mathrm{M}$ and $250 \mu \mathrm{M}$. To establish $H$. pylori growth curves, $18-20 \mathrm{~h}$ 150 bacteria cultures were diluted 100 -fold in $10 \mathrm{ml}$ of medium with or without DHA to an

151 initial OD of 0.03. Each experiment consisting in H. pylori culture incubated with DHA 152 at $100 \mu \mathrm{M}$ and $250 \mu \mathrm{M}$ and a control non-treated culture were performed in triplicate.

153 Cultures were incubated under microaerophilic conditions, as described above. 154 Every $12 \mathrm{~h}$, during a $48 \mathrm{~h}$ period, a $200 \mu \mathrm{L}$ sample of each bacterial culture was 155 isolated, the OD measured and aliquots serially diluted and plated on blood agar 156 petri dishes. After $48 \mathrm{~h}$ of incubation, the number of viable bacteria was determined 157 by colony forming units (CFU) counting.

159 Analysis of DHA and n-3 PUFAs composition in AGS cells

160 AGS cells used for fatty acid composition experiments grew in $75-\mathrm{cm}^{2}$ flasks as 161 previously described. Lipids were trans-esterified directly from the membrane pellets 162 by acid-catalysed transmethylation with methanolic- $\mathrm{HCl}\left(0.6 \mathrm{M}, 80^{\circ} \mathrm{C}, 2 \mathrm{~h}\right)$, using 163 tricosanoic acid as internal standard (Sigma). Fatty acid methyl esters (FAME) were 164 extracted with hexane, taken to dryness under a nitrogen stream, then resuspended 165 in dichloromethane and stored at $-20^{\circ} \mathrm{C}$. The chromatograph (Chrompack, CP-9001, 166 the Netherlands) was equipped with a flame ionisation detector $\left(250^{\circ} \mathrm{C}\right)$ and $\mathrm{CP}-\mathrm{Sil}$

167 88capillary column (Varian), with temperature gradient and splitless injection. EPA 168 and DHA were quantified from calibration curves with internal standard, submitted 169 to the entire analytical protocol, being expressed on a mass per cell count 170 basis.(Ranjekar et al., 2003) 


\section{Free and total cholesterol quantification}

173 AGS cells used for cholesterol profile analysis experiments grew in $75-\mathrm{cm}^{2}$ flasks as

174 previously described. Cells were then washed with PBS and the gastric cell pellets

175 were extracted with 2:1 (v/v) chloroform-methanol $(50 \mathrm{mg} / \mathrm{L} \mathrm{BHT})$, sonicated for 5

176 minutes and gently shaked overnight. Aqueous $\mathrm{NaCl}$ solution $(0.9 \%)$ was added in

177 accordance with Folchet al.(Riff et al., 2005) The lower chloroform phase was

178 collected, dehydrated with anhydrous sodium sulphate, taken to dryness under a

179 gentle $\mathrm{N}_{2}$ stream and reconstituted with hexane. Based on the initial cell counts, an

180 accurate volume of lipid solution corresponding to 100,000 cells (5 to $10 \mu \mathrm{L}$ ) was

181 spotted on a silica 60 HPTLC plate (Merck). A mixture of hexane: diethyl ether; acetic

182 acid (70:30:1) was used for elution and $13 \mathrm{mM} \alpha$-naphtol in sulphuric acid/methanol

183 (3/97; v/v; at $\left.160^{\circ} \mathrm{C}\right)$ for staining.(Riff et al., 2005) Free and esterified cholesterol

184 from Sigma (USA) was used for band identification.

185 From the remaining lipid solution, a $150 \mu \mathrm{L}$ portion was transferred to a glass micro-

186 vial and 5- $\alpha$-cholestane (Sigma) was added as internal standard. An accurate portion

187 was used for FC quantification, being taken to dryness (dessicated), derivatized with

188 N,O-Bis(trimethylsilyl)trifluoroacetamide (BSTFA) with 1\% trimethylchlorosilane

189 (TMCS) $\left(80 \mu \mathrm{l} ; 80^{\circ} \mathrm{C}, 1 \mathrm{~h}\right)$ (Fluka, Spain) and directly evaluated by gas

190 chromatography-mass spectrometry GC-MS (details below). The remaining volume

191 was used for the analysis of total cholesterol, with a previous hydrolysis $(0.36 \mathrm{M} \mathrm{KOH}$;

$19270^{\circ} \mathrm{C} ; 30^{\prime}+30^{\prime}$ ) as described by Pelletier et al. and the lipid extract derivatized as for

193 free cholesterol.(Pelletier et al., 1987) 
194 GC-MS analyses were performed on an Agilent (USA) gas chromatograph 6890 195 interfaced $\left(280^{\circ} \mathrm{C}\right)$ to a MSD-5973N mass selective detector and equipped with a 196 DB-5MS column (30 $\mathrm{m} \times 0.25 \mathrm{~mm}$ I.D., $0.25 \mu \mathrm{m}$; J\&W Scientific, USA). Electron

197 impact mass spectra were measured at acceleration energy of $70 \mathrm{eV}$. Data 198 acquisition was performed in the full-scan mode during the optimization of the 199 method (mass range 50-600). Quantification was carried out in selective ion 200 monitoring (SIM) mode with a dwell time of $30 \mathrm{~ms}$ and using the $\mathrm{m} / \mathrm{z} 129,329,353$, 201268,443 , and 458 for cholesterol, and $m / z 217,357$ and 372 for the internal 202 standard. AGS cells protein concentration was determined by Lowry's method. 203 (Lowry et al, 1951)

\section{Cholesteryl glucosides analysis}

206 Lipids were extracted as described above for the cholesterol analysis and 207 reconstituted in chloroform:methanol (2:1). Each sample was applied sequentially in

208 a 20x20 silica 60 glass plate (Merck), eluted with chloroform/methanol/ammonia 209 (40/10/0.4, vol/vol) and stained with $13 \mathrm{mM} \alpha$-naphtol in sulphuric acid/methanol 210 (3/97; v/v; at $\left.160^{\circ} \mathrm{C}\right)$ as described by Wunter et al.(Wunder et al., 2006) Glycolipids

211 isolated from $H$. pylori lipids were used as reference, after fractionation by column 212 chromatography on silicic acid and confirmation by HPTLC.(Hirai et al., 1995;

213 Shimomura et al., 2004)

214

215 Cholesterol metabolism in AGS cells upon DHA and H. pylori infection 
216 We were interested in assessing if DHA and $\mathrm{H}$. pylori infection in AGS cells impaired

217 cholesterol metabolism. 3-hydroxy-3-methylglutaryl coenzyme A reductase

218 (HMGCoA-r) is the rate-limiting enzyme in cholesterol biosynthesis that catalyses

219 mevalonate formation; Low Density Lipoprotein receptor (LDLr) is the preferential 220 receptor for cholesterol uptake in epithelial cells. (Go, W. and Mani, A., 2012) (Kaur,

221 G. et al, 2012) We have assessed both their expressions by immunoblotting. Anti222 HMGCoA-r (Upstate, 1:200), anti-LDL-r (Abcam, 1:200) and anti-a-tubulin (Sigma, 223 1:10000) as loading control were used on protein extracts from AGS cells treated 224 with DHA for 24 hours and infected with $H$. pylori strain 26695. Briefly, cells were 225 lysed in cold Catenin lysis buffer 1\% Triton X-100 (Sigma) in PBS enriched with a 226 protease inhibitor cocktail (Roche) and a phosphatase inhibitor cocktail (Sigma). The 227 proteins were quantified using a modified Bradford assay (Bio-Rad). Thirty- $\mu$ g of 228 proteins were eluted in sample buffer and loaded in $7.5 \%$ or $12 \%$ SDS-PAGE, 229 depending on the molecular mass of molecules of interest. The proteins were then 230 electroblotted onto a Hybond ECL membrane (Amersham Biosciences). Membranes 231 were blocked with 5\% non-fat milk and 0.5\% Tween-20 in PBS and immunoblotted. 232 Donkey anti-rabbit (Amersham Biosciences) or sheep anti-mouse (Amersham 233 Biosciences) HRP-conjugated secondary antibodies were used as required, 234 followed by ECL detection (Amersham Biosciences). Immunoblots were quantified 235 with the Quantity One Software (Bio-Rad).

\section{Statistical Analysis}

238 Data are expressed as mean \pm standard deviation (SD). Student's $t$-test was used 
239 to assess differences in cell lipid composition profile. All statistical tests were two-

240 sided. Differences were considered significant when $P<0.05$.

242 RESULTS

243 DHA is incorporated into AGS cells

244 Our first goal was to test if DHA was incorporated into AGS cells upon medium 245 supplementation. Cell cultures were treated with $50 \mu \mathrm{M}$ of DHA for $12 \mathrm{~h}$, a 246 concentration shown to be non-toxic according to trypan blue exclusion test (data 247 not shown). Gas chromatography was performed to assess DHA content and n-3 248 PUFAs (DHA+EPA) content in cells. As shown in Figure 1, DHA supplementation in 249 AGS cells medium significantly increased total n-3 PUFA content (4-fold compared 250 to non-DHA treated cells) and DHA content (9-fold compared to non-DHA treated 251 cells) in AGS cells, $P<0.05$. These results confirm that DHA present in the medium 252 was incorporated into AGS cells.

254 DHA decreases cholesterol availability to $H$. pylori in AGS cells

255 We postulated that DHA incorporation into AGS cells induces changes in cholesterol 256 levels. Cholesterol can be present either in a free form or esterified, depending on 257 epithelial cell dynamic and cholesterol metabolism.(Shimomura et al., 2004) 258 Fractions of total and FC were assessed by gas chromatography analysis. Results 259 presented in figure 2 correspond to the $24 \mathrm{~h}$ time-point, but all the other time-points 260 assessed reflect the same relation in cholesterol levels. DHA treatment decreased 261 total cholesterol levels $(4.4 \pm 0.8 v s 7.1 \pm 0.9 \mu \mathrm{g}$ per $\mathrm{mg}$ of cell protein), $\mathrm{P}<0.05$ (Figure 
262 2A). Similarly, the cholesterol free fraction, which is the preferential form of

263 cholesterol extracted by $H$. pylori (Shimomura et al., 2004), is significantly

264 decreased from AGS cells upon DHA treatment $(5.4 \pm 0.4 v s 2.8 \pm 0.5 \mu \mathrm{g}$ per $\mathrm{mg}$ of cell

265 protein, $\mathrm{P}<0.05$, (Figure $2 \mathrm{~A})$.

266 To confirm that $H$. pylori is indeed able to extract cholesterol from epithelial cells, we

267 incubated AGS epithelial cells with $H$. pylori and then analysed FC amounts in cells

268 after $24 \mathrm{~h}$ of infection. Both total and FC cellular levels were significantly decreased

269 by $H$. pylori infection comparatively to non-infected cells $(3.3 \pm 0.7$ vs $7.1 \pm 0.9 \mu \mathrm{g}$ per

$270 \mathrm{mg}$ of cell protein, $\mathrm{P}<0.01$, and $2.1 \pm 0.6 \mathrm{vs} 5.4 \pm 0.4 \mu \mathrm{g}$ per $\mathrm{mg}$ of cell protein,

271 respectively, $\mathrm{P}<0.05$ (Figure $2 \mathrm{~A}$ ). These results were confirmed by TLC analysis

272 showing that FC was significantly lower in AGS cells treated with $50 \mu \mathrm{M}$ of DHA or

273 incubated with $H$. pylori 26695 when compared with control cells, $\mathrm{P}<0.05$ (Figures

274 2B). In conclusion, our results indicate that DHA incorporation into AGS cells leads

275 to a decrease in the levels of total and free forms of cholesterol.

276

277 DHA treatment of cells results in a decreased cholesterol glycosylation by $\boldsymbol{H}$.

278 pylori

279 It was demonstrated that $H$. pylori glycosylates cholesterol by an enzymatic reaction

280 following its extraction from epithelial cells (Wunder et al., 2006). In order to

281 determine if the reduction of FC observed in DHA treated and infected cells results

282 in a decrease of cholesterol uptake due to $H$. pylori, we performed a TLC analysis to

283 measure cholesterol $\alpha$-glycosylation by $H$. pylori on AGS cells either pre-treated or

284 not with DHA. TLC results show that cholesterol $\alpha$-glycosylation occurs in a time 
285 dependant manner (Figure 3). Pre-treatment of AGS cells with $50 \mu \mathrm{M}$ of DHA for $12 \mathrm{~h}$

286 before the co-culture with $H$. pylori significantly decreased the synthesis of $\alpha$ -

287 glucoside cholesterol by bacteria. These results support the hypothesis that DHA

288 leads to a reduction in the availability of cell cholesterol for $H$. pylori uptake.

290 Previous exposition of $\boldsymbol{H}$. pylori to cholesterol decreases DHA anti-bacterial

291 effect

292 It was previously shown that $H$. pylori resistance to antibiotics is enhanced in the 293 presence of cholesterol. (McGee et al., 2011) Following this line of thought, we 294 decided to investigate if the sensitivity of $H$. pylori to DHA could also be dependent 295 on its access to epithelial cells' cholesterol. Briefly, AGS cells were incubated with 296 NBD-cholesterol (NBD was used for fluorescent staining of cholesterol) and treated 297 in three alternative ways: 1) incubation with DHA; 2) incubation with MBCD 298 (cholesterol removal agent); 3) no incubation, as summarized in Figure 4A. Liquid 299 cultures of $H$. pylori 26695 and SS1 were added to AGS cells at MOI of 100:1 for 3h. 300 Bacteria were then retrieved and let to grow for $48 \mathrm{~h}$ in liquid cultures either in DHA 301 free medium or in the presence of $100 \mu \mathrm{M}$ or $250 \mu \mathrm{M} \mathrm{DHA}$; these concentrations 302 were chosen because they are known to inhibit H. pylori growth (Correia et al., 2012). 303 Aliquots were collected every $12 \mathrm{~h}$ to analyse bacteria viability. As illustrated in Figure 304 4B, NBD-cholesterol was efficiently incorporated into AGS cells. H. pylori growth rate 305 and viability were neither affected by NBD-cholesterol or by MBCD treatment (data 306 not shown). 
307 The effects of DHA on the growth of $H$. pylori following exposure to cells' cholesterol 308 were analyse on strain 26695 (Figure 4C) and SS1 (Figure 4D). When H. pylori

309 uptakes NBD-cholesterol from non-treated AGS cells, the presence of $100 \mu \mathrm{M}$ of

310 DHA in the bacterial culture did not affect the bacteria growth. However, if cholesterol

311 is previously removed from AGS cells by treatment with DHA or MBCD, $100 \mu \mathrm{M}$ of

312 DHA significantly decreases $H$. pylori growth in both strains, $P<0.05$. Similar effects

313 were obtained with $250 \mu \mathrm{M}$ of $\mathrm{DHA}, \mathrm{P}<0.05$. We thus observed that the sensitivity of

314 H. pylori to DHA treatment is higher when bacteria are previously in contact with

315 cholesterol depleted cells, compared to cells with a normal level of cholesterol.

316 Hence, our results show that the direct inhibitory effect of DHA on $H$. pylori growth

317 can be modulated by the accessibility of $H$. pylori to cholesterol from the host 318 epithelial cells.

320 Cholesterol metabolism in AGS cells upon DHA and H. pylori infection

321 We have seen that DHA treatment in AGS cells regardless $\mathrm{H}$. pylori infection 322 significantly decreased the expression of both HMG-CoA reductase and LDL323 receptor. MBCD did not hold a significant effect in the expression of these proteins.

324 These results show that DHA decreases cholesterol levels through an interference 325 in cholesterol metabolism de novo synthesis. 
Discussion

327 N-3 PUFAs were identified as molecules holding an anti- $H$. pylori effect through

328 mechanisms that interfere with the bacteria's cell wall integrity.(Thompson et al., 329 1994) We have demonstrated that high concentrations of DHA, an n-3 PUFA, directly

330 inhibit H. pylori growth in vitro and its adherence to AGS cells. (Correia et al., 2012;

331 Correia et al., 2013) However, the amount of DHA shown to reduce $H$. pylori mice 332 gastric colonization was lower, suggesting that other mechanisms, in addition to the

333 DHA direct antibacterial effect on $H$. pylori, should be accountable for the reduction

334 of $H$. pylori load in the stomach of infected mice treated with DHA. Hence we 335 hypothesized that DHA might modify key properties of epithelial cells that would 336 challenge $H$. pylori infection. According to the auxotrophy of $H$. pylori for cholesterol, 337 we aimed to determine if DHA, besides its direct bactericidal effect, holds an indirect 338 action on $H$. pylori growth through modulation of cholesterol levels in the cellular 339 membrane of epithelial cells. As reported in the literature, DHA can influence lipid 340 properties of epithelial cells.(McMurray et al., 2011) It is advocated that the unique 341 hairpin structure of DHA is incompatible with cholesterol presence. Therefore, the 342 treatment of epithelial cells with DHA leads to its incorporation into membrane 343 phospholipids which will cluster unevenly into microdomains DHA-rich and DHA344 poor. As the DHA amount increases in cell membrane, cholesterol will be effluxed, 345 since DHA and cholesterol are chemically incompatible. (Dusserre et al., 1995; 346 McMurray et al., 2011) DHA is selectively incorporated into closely packed 347 phospholipids, concentrated in the inner leaflet of the cell membrane, which will 348 exclude cholesterol from the inner towards the outer leaflet of the membrane by 
350 from the outer layer can be adsorbed by lipoproteins or other molecules and the

351 efflux increases in epithelial cells.(Dusserre et al., 1995) The ability of DHA to affect

352 membrane composition and structure raised the hypothesis that DHA could have an

353 indirect effect on the ability of bacteria to survive and to colonize efficiently the gastric

354 mucosa, by modulating the availability of cholesterol to $H$. pylori uptake in gastric

355 epithelial cells, although not as efficient as MBCD that is described to remove more

356 than $80 \%$ of cell membrane cholesterol. (Francis et al., 1999) These data led us to

357 further analyse if the direct inhibitory effect of DHA on $H$. pylori growth could be 358 influenced by accessibility of bacteria to the cells' cholesterol.

359 Most interestingly, molecules that are known to lower cholesterol levels, such as 360 statins, have been shown to inhibit $H$. pylori eradication when used as co-adjuvants

361 to standard triple therapy. This occurs through a mechanism not yet elucidated. Both 362 n-3 PUFAs and statins have been shown to reduce bacterial growth in vivo, at lower 363 concentration as compared to their in vitro effect. (Bergman et al., 2011) Recently, 364 simvastatin was reported to increase the efficacy of triple therapy to eradicate $H$. 365 pylori. (Nseir et al., 2012) Altogether, these observations support that their anti-H. 366 pylori properties might be associated to their ability to interfere with cholesterol, 367 rather than their bactericidal action per se. If confirmed, this could be a major 368 breakthrough in terms of $H$. pylori infection treatment, since the involvement of 369 cholesterol metabolism as a major target for $H$. pylori therapy opens new possibilities 370 and strategies to manage the infection. 
371 In this study we show that $H$. pylori uptakes cholesterol from epithelial cells and that

372 DHA effectively lowers total cholesterol and FC in epithelial cells.(Dusserre et al.,

373 1995; Wunder et al., 2006) We have also demonstrated that according to this lower

374 level of cholesterol in epithelial cells, $H$. pylori uptakes less FC and consequently 375 produces less cholesteryl glucosides. Low levels of cholesterol in the epithelial cell

376 membrane do indeed result in less cholesterol availability to $H$. pylori uptake. This

377 feature is of utmost importance, as $H$. pylori is auxothrophic for cholesterol. It

378 extracts FC (non-esterified) from host epithelial cells, modifies it by $\alpha$-glycosylation

379 and incorporates the modified cholesteryl glucosides into its membrane.(Lee et al.,

380 2008; Patel et al., 2002; Shimomura et al., 2004; Wunder et al., 2006) This

381 dependence on cholesterol is very well illustrated by the fact that cgt knockout $H$.

382 pylori mutants that are unable to a-glycosylate cholesterol, do not colonize efficiently

383 the gerbil model.(McGee et al., 2011)

384 We have also observed that DHA interferes with cholesterol metabolism de novo 385 synthesis. Indeed, DHA is able to lower LDL-r and HMGCoA reductase (which 386 catalyses a critical step of converting HMG-CoA to mevalonic acid in the cholesterol 387 synthesis pathway) which might explain its effect in lowering cholesterol levels. This 388 reduction was already identified by others in epithelial cells, were incubation of 389 epithelial cells with DHA down-regulated the expression levels of important players

390 in cholesterol metabolism. (Goldstein, J, Brown, M, 1990)

391 Our observations propose that a previous exposition of $H$. pylori to cholesterol 392 renders the bacterium more effective in resisting the direct inhibitory effect of DHA. 393 However, if the cholesterol is previously removed by DHA or MBCD, H. pylori 
394 becomes more sensitive to DHA exposure. These results indicate that $H$. pylori 395 accessibility to cholesterol improves the resistance of the bacteria to the inhibitory 396 growth effect of DHA. This increased resistance was also shown with antibiotics. In 397 the same sense MBCD, which depletes epithelial cell cholesterol, is known to 398 abrogate H. pylori infection both in vitro and in vivo, (Hildebrandt and McGee, 2009; 399 Lai et al., 2008) Although the physiologic significance of incorporation of cholesterol 400 and its derivatives into the H. pylori membrane is still not well established, our results

401 support the hypothesis that cholesterol assimilation is important for $H$. pylori's 402 survival and growth.(Shimomura et al., 2004; Trainor et al., 2011)

403 In conclusion, in the present study, we have shown that DHA is efficiently 404 incorporated into epithelial cells and is able to decrease cell membrane cholesterol 405 levels, which confirms its recognized role in modulating the lipid profile of the cell 406 membrane.(Rockett et al., 2011) DHA also decreases cholesterol de novo synthesis 407 which overall can explain the decrease in cholesterol levels. Our findings also 408 demonstrate that DHA decreases cholesterol uptake by H. pylori from epithelial cells, 409 and that $H$. pylori sensitivity to DHA can be influenced by a previous exposure to 410 cholesterol. These results are in line with reported observations showing that $H$. 411 pylori that grows with cholesterol is up to thousand-fold more resistant to amoxicillin 412 treatment than $H$. pylori grown in cholesterol-depleted medium.(McGee et al., 2011) 413 H. pylori cholesterol-dependent resistance to some anti-Helicobacter molecules 414 such as bile salts, is also documented.(Trainor et al., 2011) Previous studies have 415 implicated cholesterol as a crucial component for antibiotics resistance, which would 416 enable it to modulate therapies efficiency. This concept may be very important for 
417 the management of $H$. pylori infection since it supports the important notion that the 418 resistance of $H$. pylori to some antimicrobial compounds, which are or could be used 419 clinically to eradicate the infection, can be modulated by cholesterol uptake. 420 (Testerman et al., 2006; Trainor et al., 2011)

421 


\section{Acknowledgments}

423 This study was supported by the ERA-NET Pathogenomics (ERA-PTG/0001/2010)

424 and by the Portuguese Foundation for Science and Technology (FCT - PTDC/SAU-

425 SAP/120024/2010 and PTDC/BIA-MIC/116890/2010). Marta Correia is supported by

426 an FCT fellowship BD/36689/2007. The Acções integradas Luso-Francesas (CRUP-

427 PAULIF) Portugal and France also provided financial support (AF-8/09). IPATIMUP

428 is an Associate Laboratory of the Portuguese Ministry of Science, Technology and

429 Higher Education and is partially supported by the FCT.

430

431 
433 Applegate, K.R., Glomset, J.A., 1986. Computer-based modeling of the conformation and packing properties of docosahexaenoic acid. Journal of lipid research 27, 658-680. Bergman, P., Linde, C., Putsep, K., Pohanka, A., Normark, S., Henriques-Normark, B., Andersson, J., Bjorkhem-Bergman, L., 2011. Studies on the antibacterial effects of statins-in vitro and in vivo. PloS one 6, e24394.

438 Correia, M., Michel, V., Matos, A.A., Carvalho, P., Oliveira, M.J., Ferreira, R.M., Dillies, 439 M.A., Huerre, M., Seruca, R., Figueiredo, C., Machado, J.C., Touati, E., 2012. Docosahexaenoic Acid Inhibits Helicobacter pylori Growth In Vitro and Mice Gastric Mucosa Colonization. PloS one 7, e35072.

Correia, M., Michel, V., Osorio, H., El Ghachi, M., Bonis, M., Boneca, I.G., De Reuse, H., Matos, A.A., Lenormand, P., Seruca, R., Figueiredo, C., Machado, J.C., Touati, E., 2013. Crosstalk between Helicobacter pylori and Gastric Epithelial Cells Is Impaired by Docosahexaenoic Acid. PloS one 8, e60657.

Dusserre, E., Pulcini, T., Bourdillon, M.C., Ciavatti, M., Berthezene, F., 1995. Omega-3 fatty acids in smooth muscle cell phospholipids increase membrane cholesterol efflux. Lipids 30, 35-41.

Francis, S.A., Kelly, J.M., McCormack, J., Rogers, R.A., Lai, J., Schneeberger, E.E., Lynch, R.D., 1999. Rapid reduction of MDCK cell cholesterol by methyl-beta-cyclodextrin alters steady state transepithelial electrical resistance. Eur J Cell Biol 78, 473-484.

Gisbert, J.P., Calvet, X., O'Connor, A., Megraud, F., O'Morain, C.A., 2010. Sequential therapy for Helicobacter pylori eradication: a critical review. J Clin Gastroenterol 44, 313325.

Go, G. W., Mani, A. 2012. Low-density lipoprotein receptor (LDLR) family orchestrates cholesterol homeostasis. Yale J Biol Med, 85(1):19-28.

Goldstein, J, Brown, M. 1990. Regulation of mevalonate pathway. Nature, 343 (6257):425430

Hildebrandt, E., McGee, D.J., 2009. Helicobacter pylori lipopolysaccharide modification, Lewis antigen expression, and gastric colonization are cholesterol-dependent. BMC microbiology 9, 258.

Hirai, Y., Haque, M., Yoshida, T., Yokota, K., Yasuda, T., Oguma, K., 1995. Unique cholesteryl glucosides in Helicobacter pylori: composition and structural analysis. Journal of bacteriology 177, 5327-5333.

Kaur, G., Sinclair, A. J., Cameron-Smith, D., Barr, D. P., Molero-Navajas, J. C., Konstantopoulos, N.2011. Docosapentaenoic acid (22:5n-3) down-regulates the expression of genes involved in fat synthesis in liver cells. 85(3-4):155-61.

Knapp, H.R., Hullin, F., Salem, N., Jr., 1994. Asymmetric incorporation of dietary n-3 fatty acids into membrane aminophospholipids of human erythrocytes. Journal of lipid research 35, 1283-1291.

Lai, C.H., Chang, Y.C., Du, S.Y., Wang, H.J., Kuo, C.H., Fang, S.H., Fu, H.W., Lin, H.H., Chiang, A.S., Wang, W.C., 2008. Cholesterol depletion reduces Helicobacter pylori CagA translocation and CagA-induced responses in AGS cells. Infect Immun 76, 3293-3303.

Lee, A., O'Rourke, J., De Ungria, M.C., Robertson, B., Daskalopoulos, G., Dixon, M.F., 1997. A standardized mouse model of Helicobacter pylori infection: introducing the Sydney strain. Gastroenterology 112, 1386-1397. 
Lee, H., Wang, P., Hoshino, H., Ito, Y., Kobayashi, M., Nakayama, J., Seeberger, P.H., Fukuda, M., 2008. Alpha1,4GlcNAc-capped mucin-type O-glycan inhibits cholesterol alphaglucosyltransferase from Helicobacter pylori and suppresses $\mathrm{H}$. pylori growth. Glycobiology $18,549-558$.

Lowry, O. H., Rosebrough, N. J., Farr, A. L., Randall, R. J.1951. Protein measurement with the Folin phenol reagent. J Biol Chem, 193(1):265-75.

Malfertheiner, P., Megraud, F., O'Morain, C., Bazzoli, F., El-Omar, E., Graham, D., Hunt, R., Rokkas, T., Vakil, N., Kuipers, E.J., 2007. Current concepts in the management of Helicobacter pylori infection: the Maastricht III Consensus Report. Gut 56, 772-781. McGee, D.J., George, A.E., Trainor, E.A., Horton, K.E., Hildebrandt, E., Testerman, T.L., 2011. Cholesterol enhances Helicobacter pylori resistance to antibiotics and LL-37. Antimicrob Agents Chemother 55, 2897-2904.

McMurray, D.N., Bonilla, D.L., Chapkin, R.S., 2011. n-3 Fatty acids uniquely affect antimicrobial resistance and immune cell plasma membrane organization. Chem Phys Lipids 164, 626-635.

Nseir, W., Diab, H., Mahamid, M., Abu-Elheja, O., Samara, M., Abid, A., Mograbi, J., 2012. Randomised clinical trial: simvastatin as adjuvant therapy improves significantly the Helicobacter pylori eradication rate--a placebo-controlled study. Aliment Pharmacol Ther 36, 231-238.

Patel, H.K., Willhite, D.C., Patel, R.M., Ye, D., Williams, C.L., Torres, E.M., Marty, K.B., MacDonald, R.A., Blanke, S.R., 2002. Plasma membrane cholesterol modulates cellular vacuolation induced by the Helicobacter pylori vacuolating cytotoxin. Infect Immun 70, 4112-4123.

Peek, R.M., Jr., Crabtree, J.E., 2006. Helicobacter infection and gastric neoplasia. J Pathol 208, 233-248.

Pelletier, O., Wright, L.A., Breckenridge, W.C., 1987. Isotope dilution/mass spectrometry of serum cholesterol with [3,4-13C]cholesterol: proposed definitive method. Clinical chemistry 33, 1403-1411.

Ranjekar, P.K., Hinge, A., Hegde, M.V., Ghate, M., Kale, A., Sitasawad, S., Wagh, U.V., Debsikdar, V.B., Mahadik, S.P., 2003. Decreased antioxidant enzymes and membrane essential polyunsaturated fatty acids in schizophrenic and bipolar mood disorder patients. Psychiatry research 121, 109-122.

Riff, J.D., Callahan, J.W., Sherman, P.M., 2005. Cholesterol-enriched membrane microdomains are required for inducing host cell cytoskeleton rearrangements in response to attaching-effacing Escherichia coli. Infect Immun 73, 7113-7125.

Rockett, B.D., Franklin, A., Harris, M., Teague, H., Rockett, A., Shaikh, S.R., 2011. Membrane raft organization is more sensitive to disruption by (n-3) PUFA than nonraft organization in EL4 and B cells. J Nutr 141, 1041-1048.

Shaikh, S.R., Dumaual, A.C., Castillo, A., LoCascio, D., Siddiqui, R.A., Stillwell, W., Wassall, S.R., 2004. Oleic and docosahexaenoic acid differentially phase separate from lipid raft molecules: a comparative NMR, DSC, AFM, and detergent extraction study. Biophys J 87, 1752-1766.

Shimomura, H., Hayashi, S., Yokota, K., Oguma, K., Hirai, Y., 2004. Alteration in the composition of cholesteryl glucosides and other lipids in Helicobacter pylori undergoing morphological change from spiral to coccoid form. FEMS Microbiol Lett 237, 407-413. 
Talley, N.J., Fock, K.M., Moayyedi, P., 2008. Gastric Cancer Consensus conference recommends Helicobacter pylori screening and treatment in asymptomatic persons from high-risk populations to prevent gastric cancer. The American journal of gastroenterology 525 103, 510-514.

526 Testerman, T.L., Conn, P.B., Mobley, H.L., McGee, D.J., 2006. Nutritional requirements and 527 antibiotic resistance patterns of Helicobacter species in chemically defined media. Journal of 528 clinical microbiology 44, 1650-1658.

529 Thompson, L., Cockayne, A., Spiller, R.C., 1994. Inhibitory effect of polyunsaturated fatty 530 acids on the growth of Helicobacter pylori: a possible explanation of the effect of diet on 531 peptic ulceration. Gut 35, 1557-1561.

532 Trainor, E.A., Horton, K.E., Savage, P.B., Testerman, T.L., McGee, D.J., 2011. Role of the 533 HefC efflux pump in Helicobacter pylori cholesterol-dependent resistance to ceragenins and 534 bile salts. Infection and immunity 79, 88-97.

535 Wang, H.J., Cheng, W.C., Cheng, H.H., Lai, C.H., Wang, W.C., 2012. Helicobacter pylori 536 cholesteryl glucosides interfere with host membrane phase and affect type IV secretion 537 system function during infection in AGS cells. Mol Microbiol 83, 67-84.

538 Wunder, C., Churin, Y., Winau, F., Warnecke, D., Vieth, M., Lindner, B., Zahringer, U., 539 Mollenkopf, H.J., Heinz, E., Meyer, T.F., 2006. Cholesterol glucosylation promotes immune 540 evasion by Helicobacter pylori. Nat Med 12, 1030-1038.

541 Xiong, Q., Lin, M., Rikihisa, Y., 2009. Cholesterol-dependent anaplasma phagocytophilum 542 exploits the low-density lipoprotein uptake pathway. PLoS Pathog 5, e1000329. 
Figures legend

547 Figure 1Quantification of n-3 PUFA and DHA in gastric epithelial cells. AGS cells

548 were incubated with DHA $50 \mu \mathrm{M}$ for $12 \mathrm{~h}$. Incorporation of $\mathrm{n}-3$ PUFA and DHA was

549 quantified by Gas Chromatography as described in material and methods. Student's

550 t-test was performed to assess differences between AGS control cells and DHA

551 treated cells. DHA content and n-3 PUFAs content in AGS cells were significantly

552 different in DHA treated cells compared to non-treated cells, $p<0.05$. Results are

553 expressed as fold-increase compared with normalized control levels. Data are

554 expressed as the mean \pm standard deviation and are representative of three 555 independent experiments.

557 Figure 2: Cholesterol levels in DHA-treated and H. pylori-infected AGS cells for 24

558 hours. A) Both DHA treatment and H. pylori infection decreased the levels of total 559 cholesterol and free cholesterol in AGS cells. Results are expressed as $\mu \mathrm{g}$ of

560 cholesterol per mg of cell protein. B) Free and esterified cholesterol levels in AGS 561 cells treated with DHA and incubated with H. pylori 26695 were assessed by TLC.

562 C) Cholesterol metabolism in AGS cells in terms of expression of LDL-receptor and 563 HMG-CoA reductase by Western Blot analysis.

565 Figure 3: H. pylori enzymatic glycosylation of cholesterol assessed by Thin Layer 566 Chromatography (TLC).

567 Liquid cultures of $H$. pylori 26695 were added to AGS cells previously treated or not 568 with $50 \mu \mathrm{M}$ of DHA. Cholesterol $\alpha$-glycosylation significantly increased with $H$. pylori 
569 incubation time $(p<0.05)$ in the absence of DHA treatment. Cholesterol $\alpha-$

570 glycosylation was significantly decreased in AGS cells treated with $50 \mu \mathrm{M}$ of DHA in

571 comparison with AGS cells not treated with DHA in all time points (one, six and $24 \mathrm{~h}$

572 of $H$. pylori incubation), $\mathrm{p}<0.01$.

573

574 Figure 4: DHA efficiency in inhibiting $H$. pylori growth depends on the previous

575 uptake of cholesterol by H. pylori. A) Description of the experiment: AGS cells were

576 grown as described until reaching monolayers of cells, incubated with NBD-

577 cholesterol for $3 \mathrm{H}$ and treated in three alternative ways: 1) incubation with DHA for

57812 hours; 2) incubation with MBCD for 1 hour; 3) no incubation. Then, liquid cultures

579 of $H$. pylori 26695 and SS1 were added to the AGS cells for 3h; the pelleted $H$. pylori

580 was then grown in liquid cultures without DHA, with $100 \mu \mathrm{M}$ of DHA, or with $250 \mu \mathrm{M}$

581 of DHA, for 48h. B) AGS cells were grown on glass coverslips. AGS cells were

582 preloaded with NBD-cholesterol. Samples were analyzed by laser scanning

583 microscopy (magnification 40x). The experiment shows that NBD-cholesterol was

584 effectively incorporated into AGS cells following a $3 \mathrm{~h}$ incubation period (green

585 staining represents NBD-cholesterol in AGS cells). C) Impact of cholesterol previous

586 uptake on the inhibitory growth effect of DHA on H. pylori. Data are expressed as

587 the mean \pm standard deviation and are representative of three independent

588 experiments. * (asterisk) Refers to significant differences in H. pylori growth between

589 cells exposed to cholesterol and DHA-treated, MBCD-treated and AGS cells non-

590 treated.

591 


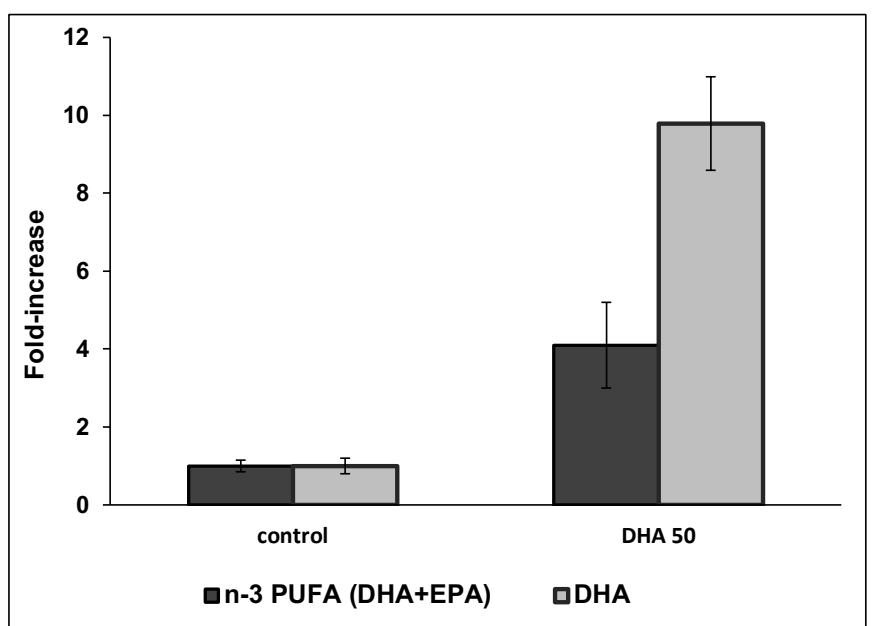

592

$593 \quad$ Figure 1 
A

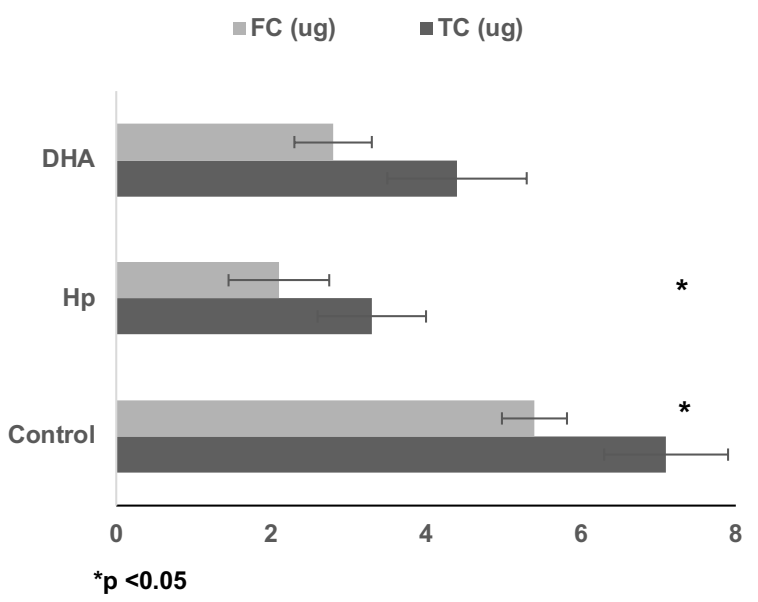

B

DHA treated cells

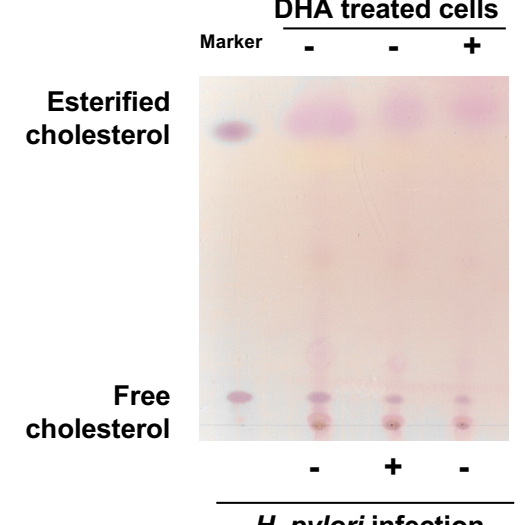

H. pylori infection in AGS cells

C
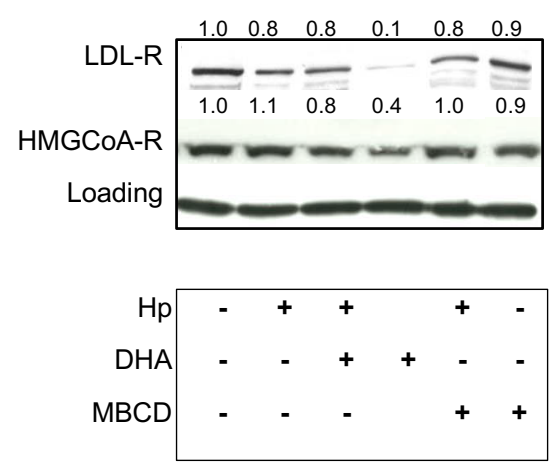

Figure 2 


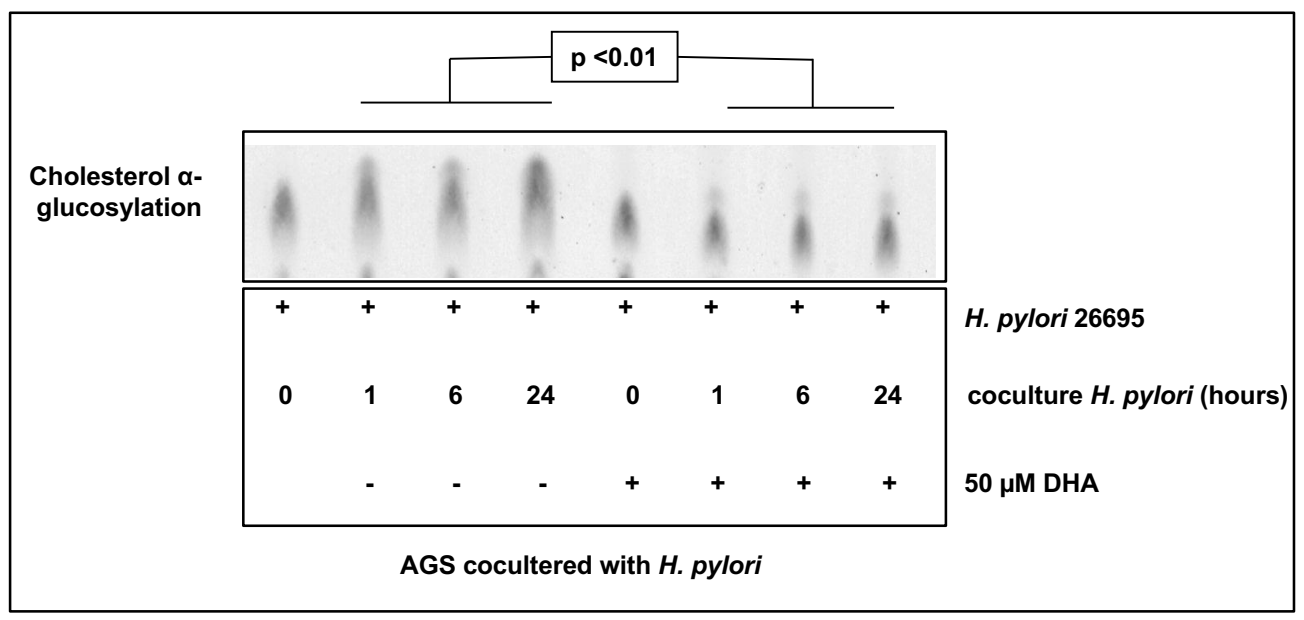

Figure 3 
A

NBD-cholesterol

(5 $\mu \mathrm{g} / \mathrm{ml} ; 3 \mathrm{H})$

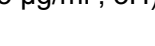

H. pylori 26695

H. pylori SS1

MOI 1:100 (3H) pelleted bacteria and DHA treatment $(\mu \mathrm{M})$
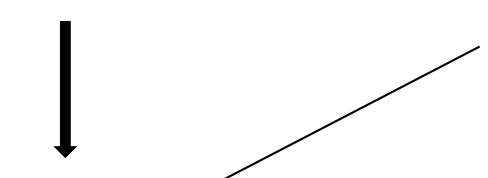

DHA

( $\downarrow$ cholesterol levels)

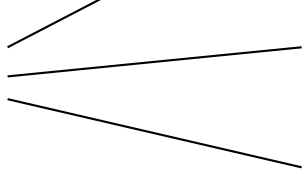

100

250

0

100

250

0

100

250

(normal cholesterol levels)

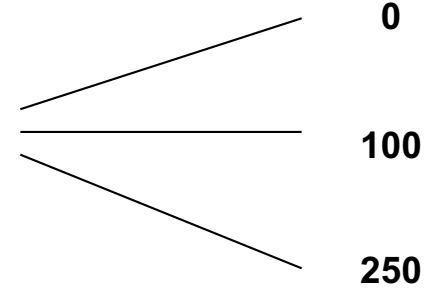

B

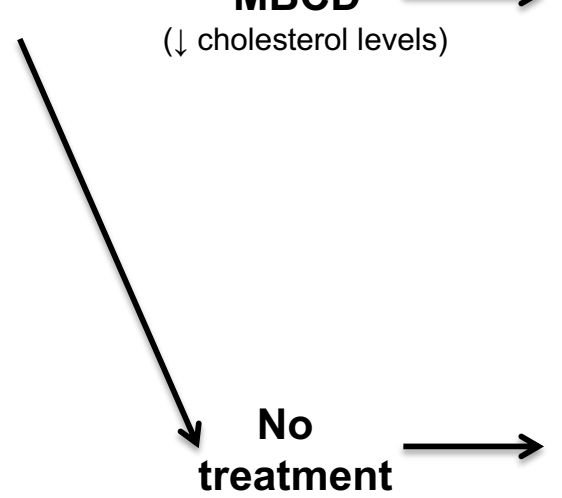

Without NBD-cholesterol

With NBD-cholesterol
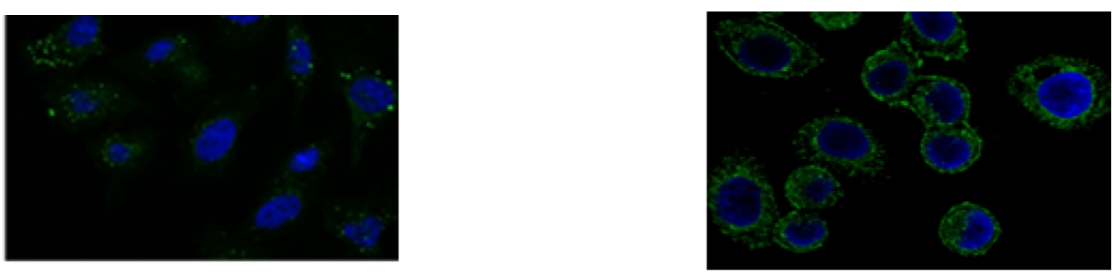

600 
C

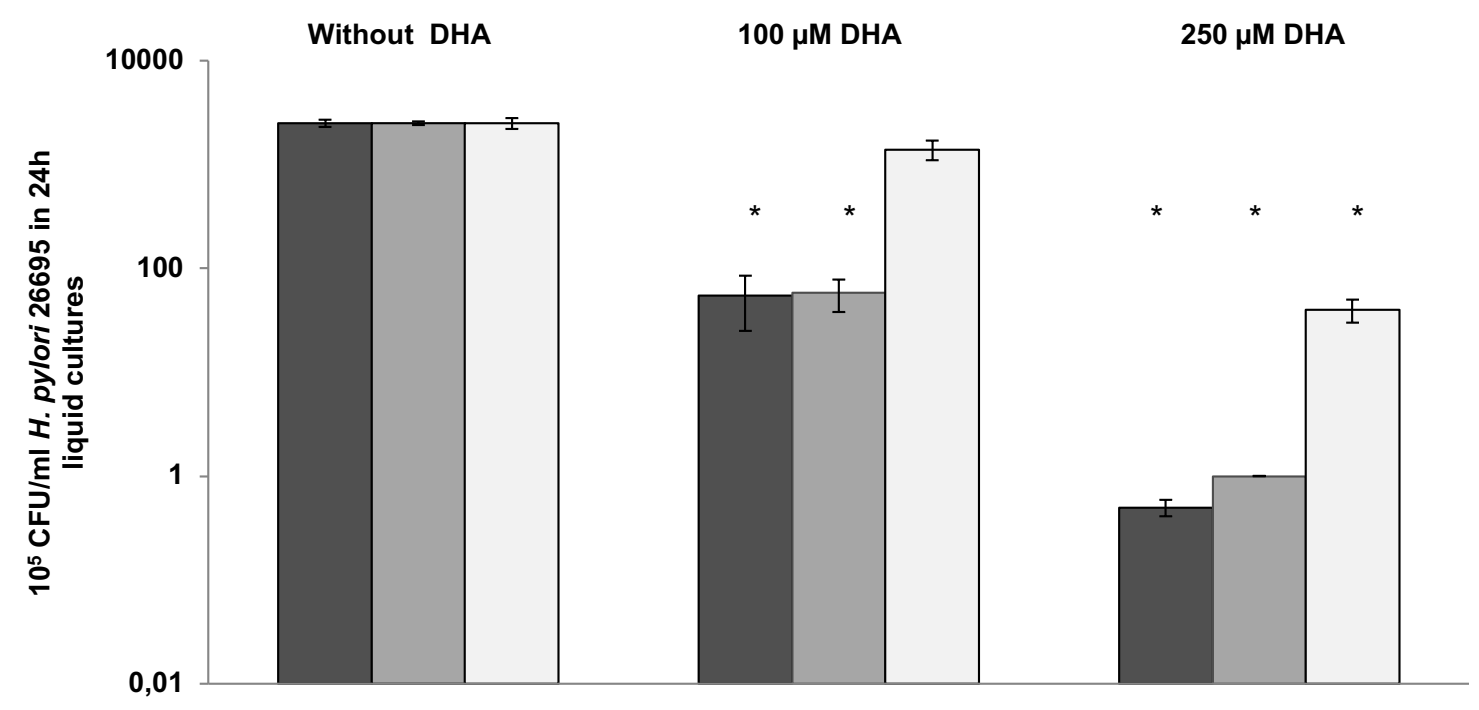

$\square$ Decrease in AGS cholesterol (MBCD) $\square$ decrease in AGS cholesterol (DHA) $\square$ Without addition of cholesterol depletion agents

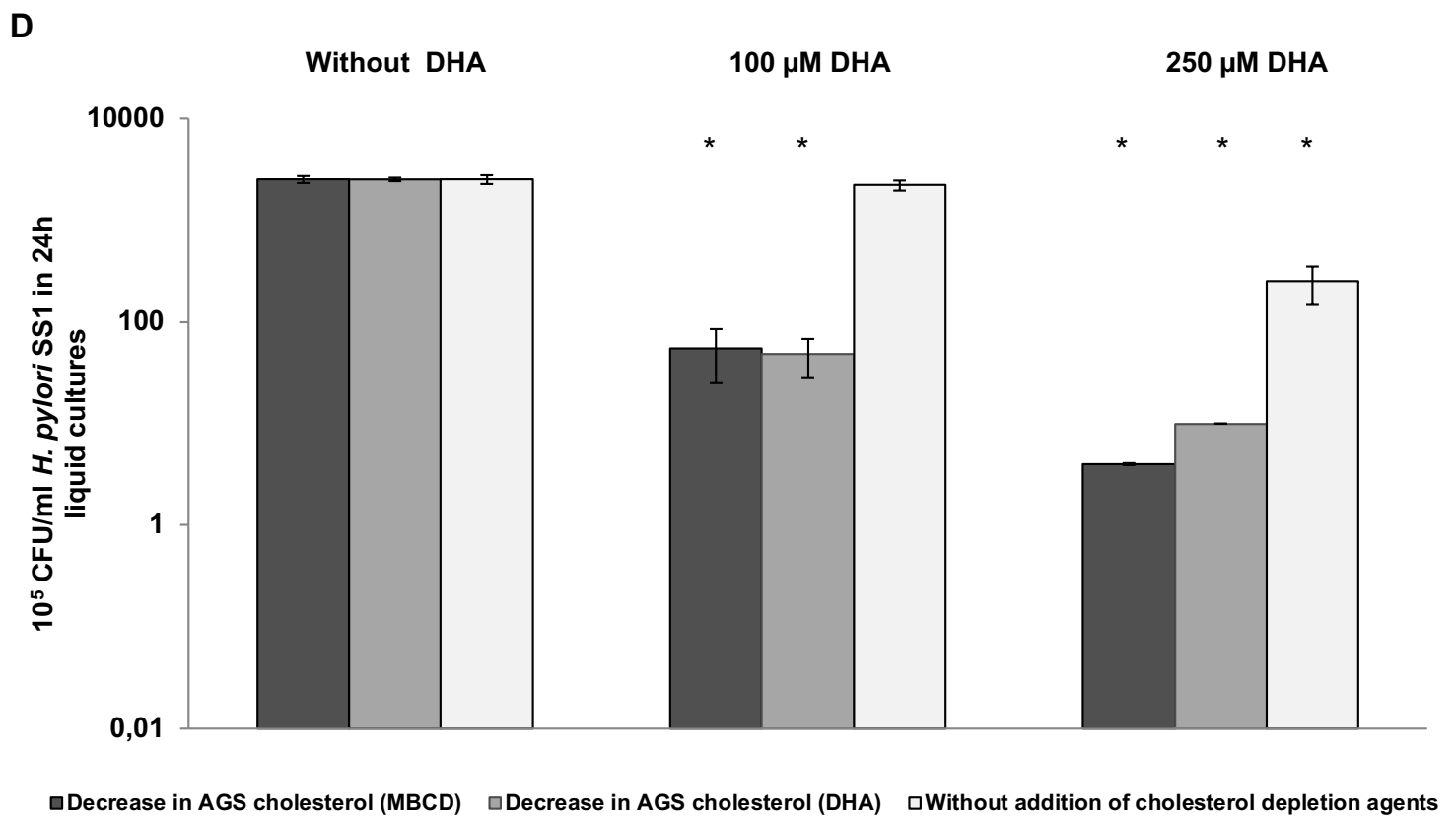

Figure 4 